\title{
Sr Isotopic Composition of NIES Certified Reference Material No. 28 Urban Aerosols
}

\begin{abstract}
Akane Yamakawa ${ }^{1 *}$, Kimiyo Nagano ${ }^{1}$, Miyuki Ukachi ${ }^{1}$, Kaoru Onishi $^{1}$, Katsuyuki Yamashita ${ }^{2}$, Tomoki Shibata $^{3}$, Kazunari Takamiya ${ }^{3}$, Tomomi Kani ${ }^{4}$, Sylvain Bérail ${ }^{5}$, Olivier F. X. Donard ${ }^{5}$ and David Amouroux ${ }^{4}$

${ }^{1}$ Environmental Standards Section, Center for Environmental Standards and Measurement, Health and Environmental Risk Division, National Institute for Environmental Studies, Ibaraki, Japan, ${ }^{2}$ Academic Field of Natural Science and Technology, Academic Research Assembly, Okayama University, Okayama, Japan, ${ }^{3}$ Graduate School of Natural Science and Technology, Okayama University, Okayama, Japan, ${ }^{4}$ Faculty of Advanced Science and Technology, Division of Natural Science Earth and Environmental Science, Kumamoto University, Kumamoto, Japan, ${ }^{5}$ E2S UPPA, CNRS, IPREM, Institut des Sciences Analytiques et de Physico-chimie pour l'Environnement et les Matériaux, Universite de Pau et des Pays de l'Adour, Pau, France
\end{abstract}

An interlaboratory study of the National Institute for Environmental Studies (NIES) certified reference material (CRM) No. 28 Urban Aerosols collected from the filters of a central ventilating system in a building in the Beijing city center from 1996 to 2005 was performed to obtain an information value of the Sr isotopic composition. The Sr isotopic composition was measured using multi-collector-inductively coupled plasma-mass spectrometry (MCICP-MS) to confirm the CRM's within- and between-bottle homogeneity, and the results showed a ${ }^{87} \mathrm{Sr} /{ }^{86} \mathrm{Sr}$ ratio of $0.710227 \pm 0.000019$ (2SD, $n=18$ ). The $\mathrm{Sr}$ isotopic compositions were intercompared using thermal ionization mass spectrometry (TIMS), which showed good agreement with values obtained at NIES. Subsequently, a consistent ${ }^{87} \mathrm{Sr} /{ }^{86} \mathrm{Sr}$ ratio was observed between two dissolution (hotplate $v s$. high-pressure bomb) and $\mathrm{Sr}$ separation (Sr spec resin vs. cation exchange resin) methods. To validate and reproduce the accuracy of our analytical methods, the $\mathrm{Sr}$ isotopic compositions of secondary reference materials, JB-1b and JA-2, were also measured. Our results showed that NIES CRM No. 28 is appropriate for the quality control of Sr isotope measurements of particulate matter analyses for environmental and geochemical studies.

Keywords: Sr isotopes, atmospheric particles, MC-ICP-MS, TIMS, NIES CRM

\section{INTRODUCTION}

Atmospheric particulate matter (PM) is a complex mixture of particles with diverse chemical compositions and sizes. The chemical compositions vary depending on their source (natural vs. anthropogenic), environmental condition (e.g., temperature, humidity, and redox condition), and atmospheric processing (e.g., radiation, convection, and transport). PM emissions from urban and industrial areas are a critical environmental problem that affects the climate, human health, visibility, biogeochemical cycles, and atmospheric chemistry. Identifying the source(s) of emitted PM is critical for providing scientific strategies to improve air quality.

Recent studies have assessed the utility of strontium $(\mathrm{Sr})$ isotopes ${ }^{87} \mathrm{Sr} /{ }^{86} \mathrm{Sr}$ to identify sources of atmospheric PM (e.g., Capo et al., 1998; Kanayama et al., 2002; Grousset and Biscaye, 2005; Lahd Geagea et al., 2008; Widory et al., 2010; Duarte et al., 2017). Sr has four natural isotopes: ${ }^{84} \mathrm{Sr},{ }^{86} \mathrm{Sr}$, 
${ }^{87} \mathrm{Sr}$, and ${ }^{88} \mathrm{Sr} .{ }^{87} \mathrm{Sr}$ is a radiogenic isotope of ${ }^{87} \mathrm{Rb}$ by $\beta$-decay (half-life $=4.88 \times 10^{10}$ years; De Laeter et al., 2003). Due to an initial difference in $\mathrm{Rb} / \mathrm{Sr}$ and age-integrated effects, the ${ }^{87} \mathrm{Sr} /{ }^{86} \mathrm{Sr}$ ratios of Earth surface materials vary widely (e.g., more radiogenic ancient crustal rock or less radiogenic carbonate as the parent materials of soil). Therefore, $\mathrm{Sr}$ isotope ratios measured at a receptor site provide clues to the source of the $\mathrm{Sr}$ or the mixing ratio of multiple sources. For example, a previous study on atmospheric PM in Beijing indicated that atmospheric Sr was mainly controlled by coal combustion and to a lesser extent by cement plants and/or smelters (Widory et al., 2010).

To characterize emission sources, accurate methods for determining $\mathrm{Sr}$ isotopic ratios in $\mathrm{PM}$ are required, and matrix matching between samples and standards is important for the quality control of the analysis. Currently, the NIES and other research institutes (e.g., National Institute of Standards and Technology and the European Commission Joint Research Center-Institute for Reference Materials and Measurements) provide commercially available standard aerosol reference materials; however, $\mathrm{Sr}$ isotopic compositions of PM reference materials have not been reported. To overcome this limitation, we aim to obtain an information value of the ${ }^{87} \mathrm{Sr} /{ }^{86} \mathrm{Sr}$ ratio for NIES CRM No. 28 Urban Aerosols. The objectives of this study are: (i) to determine the $\mathrm{Sr}$ isotope distribution within and between the bottles of the CRM using multi-collector-inductively coupled plasma-mass spectrometry (MC-ICP-MS); (ii) to confirm the consistency of the interlaboratory CRM isotopic ratio using two types of instruments, MC-ICP-MS vs. thermal ionization mass spectrometry (TIMS); and (iii) to confirm the consistency of the $\mathrm{Sr}$ isotopic composition using different digestion methods (hotplate vs. high-pressure bomb) and $\mathrm{Sr}$ separation methods ( $\mathrm{Sr}$ spec resin vs. cation exchange resin).

\section{MATERIALS AND METHODS}

\section{Reagents}

All acids used in this study were Ultrapure-100 (Kanto Chemical Co., Inc., Japan), and aqueous solutions were prepared using Milli-Q water (Japan Millipore Ltd., Japan) at NIES. At Okayama University, EL grade $70 \% \mathrm{HNO}_{3}$ (Kanto Chemical Co., Inc., Japan) was twice distilled without dilution using a Teflon still. EL grade 36\% HCl (Kanto Chemical Co., Inc., Japan) was diluted to $\sim 6 \mathrm{M}$ using Milli-Q water and then twice distilled using a Teflon still. TAMAPURE-AA-100 $\mathrm{HClO}_{4}$ (Tama Chemicals Co., Ltd., Japan) was used without further purification.

\section{Samples}

\section{NIES CRM No. 28}

NIES CRM No. 28 Urban Aerosols, collected from the filters of a central ventilating system of a building located in Beijing city center, was produced to evaluate the analytical accuracy of determining the mass fraction of selected elements (18 certified and 14 reference values) (Mori et al., 2008). The certified value of $\mathrm{Sr}$ is $469 \pm 16 \mathrm{mg} / \mathrm{kg}$ (certificate is available on https://www.nies.go.jp/labo/crm-e/hrfba300000ble6p-att/No.
28_E.pdf). The Hg isotopic composition was also determined as an information value for the CRM (Yamakawa et al., 2020).

\section{JA-2 and JB-1b}

$\mathrm{Sr}$ isotopic measurements of the secondary reference, JA-2 and JB- $1 \mathrm{~b}$, were performed using the same methods to manage the analytical accuracy of our method. These geological samples were produced at the Geological Survey of Japan in the National Institute of Advanced Industrial Science and Technology. The ${ }^{87} \mathrm{Sr} /{ }^{86} \mathrm{Sr}$ ratios of JA-2 and JB-1b are reported in Miyazaki and Shuto (1998) and Yuhara et al. (2000), respectively.

\section{NIST SRM 987}

NIST SRM 987 was prepared at each laboratory by the following methods. At NIES and Kumamoto University, strontium carbonate powder was dissolved in dilute $\mathrm{HNO}_{3}$ to make a stock solution. The solution was then adjusted to $300 \mathrm{ng} \mathrm{g}^{-1}$ in $2 \% \mathrm{HNO}_{3}$ for the isotope measurement. At Okayama University, a $\sim 1 \mu \mathrm{g} \mathrm{ml}^{-1}$ stock solution of NIST SRM 987 was prepared by dissolving strontium carbonate powder in dilute $\mathrm{HCl}$.

\section{Sample Preparation Sample Decomposition}

Three bottles (bottle No. 044, 375, and 597) were randomly selected to assess the between- and within-bottle homogeneity of $\mathrm{Sr}$ isotope. The three subsamples were taken from each bottle and decomposed on a hotplate with a concentrated acid mixture of $\mathrm{HNO}_{3} / \mathrm{HClO}_{4} / \mathrm{HF}$. Approximately $100 \mathrm{mg}$ of powdered samples of the CRM, JA-2 and JB- $1 \mathrm{~b}$ were weighed and decomposed overnight in $5 \mathrm{ml}$ of $\mathrm{HNO}_{3}$ at $140^{\circ} \mathrm{C}$. Then, $2 \mathrm{ml}$ of $7 \mathrm{M} \mathrm{HClO}_{4}$ was added and heated overnight at $200^{\circ} \mathrm{C}$ and dried to $1 \mathrm{ml}$. A mixture of $2 \mathrm{ml}$ of $13 \mathrm{M} \mathrm{HNO}_{3}, 1 \mathrm{ml}$ of $7 \mathrm{M} \mathrm{HClO}_{4}$, and $1 \mathrm{ml} 30 \mathrm{M} \mathrm{HF}$ was added and heated for $2 \mathrm{~h}$. The decomposed samples were heated to dryness at $200^{\circ} \mathrm{C}$ by step heating. The resulting sample cake was redissolved in $1 \mathrm{ml}$ of $3 \mathrm{M}$ $\mathrm{HNO}_{3}$, and the insoluble fraction was removed by centrifuging. This procedure was repeated several times, and the supernatant was subjected to the following chemical separation.

At Okayama University, the Sr isotope ratios were investigated using different acid decomposition and Sr separation methods. To obtain a representative sample, approximately $200 \mathrm{mg}$ of powdered sample (bottle No. 35) was digested. The sample was dissolved in an $\mathrm{HF} / \mathrm{HNO}_{3}$ mixture using Teflon capsules sealed in stainless steel bombs for $72 \mathrm{~h}$ at $190^{\circ} \mathrm{C}$. Once complete digestion was achieved, the sample was transferred to a $15 \mathrm{ml}$ Teflon vial and $0.2 \mathrm{ml}$ of $\mathrm{HClO}_{4}$ was added before drying down at $120^{\circ} \mathrm{C}-200^{\circ} \mathrm{C}$. The evaporated sample was further treated in $0.2 \mathrm{ml}$ of $\mathrm{HClO}_{4}$ to avoid fluoride precipitation. The sample was subsequently dissolved in $\mathrm{HCl}$ and $\sim 25 \%$ split was taken for $\mathrm{Sr}$ isotopic analysis.

\section{Chemical Separation}

Sr was separated from the other elements, particularly Rb, in the digest using Sr spec resin (Eichrom Technologies, US) at NIES. One milliliter of $\mathrm{Sr}$ spec resin was packed in a size $\mathrm{S}$ polypropylene column (Muromachi Chemical Inc., Japan). The resin was cleaned by passing $3 \mathrm{ml}$ of $3 \mathrm{M} \mathrm{HCl}, 18 \mathrm{ml}$ of $0.05 \mathrm{M}$ 
TABLE 1 | Details of the operational parameters of the MC-ICP-MS (Nu Plasma II; Nu Instruments, UK) at NIES.

\begin{tabular}{|c|c|}
\hline Instrumentation & Nu Plasma II \\
\hline Monitored isotopes & $\begin{array}{c}88(\mathrm{Sr}), 87(\mathrm{Sr}, \mathrm{Rb}), 86(\mathrm{Sr}, \mathrm{Kr}), 85(\mathrm{Rb}) \text {, } \\
84(\mathrm{Sr}, \mathrm{Kr}), 83(\mathrm{Kr}) \text {, and } 82(\mathrm{Kr})\end{array}$ \\
\hline RF power & $1300 \mathrm{~W}$ \\
\hline Plasma gas & 13.0 L min $\mathrm{Lin}^{-1}$ \\
\hline Auxiliary & $0.8 \mathrm{~L} \mathrm{~min}^{-1}$ \\
\hline Nebulization & $1.0 \mathrm{~L} \mathrm{~min}^{-1}$ \\
\hline Integration time & $8 \mathrm{sec}$ \\
\hline Number of cycles per block & 20 cycle/block \\
\hline Number of blocks & 4 blocks \\
\hline $\begin{array}{l}\text { Sr concentrations of sample and } \\
\text { standard }\end{array}$ & $300 \mathrm{ng} \mathrm{g}^{-1}$ \\
\hline Sensitivity of sample and standard $\left({ }^{88} \mathrm{Sr}\right)$ & $\sim 10 \times 10^{-11} \mathrm{~A}$ \\
\hline
\end{tabular}

$\mathrm{HNO}_{3}$, and $3 \mathrm{ml}$ of $3 \mathrm{M} \mathrm{HNO}_{3}$. The sample dissolved in $1 \mathrm{ml}$ of $3 \mathrm{M} \mathrm{HNO}_{3}$ was loaded onto the column after conditioning the resin using $1 \mathrm{ml}$ of $3 \mathrm{M} \mathrm{HNO}_{3}$. The fraction containing $\mathrm{Rb}$ (and $\mathrm{Ca}, \mathrm{K}, \mathrm{Mg}, \mathrm{Ba}$, etc.), which began eluting immediately, was discarded by passing an additional $3 \mathrm{ml}$ of $3 \mathrm{M} \mathrm{HNO}_{3}, 4 \mathrm{ml}$ of $6 \mathrm{M} \mathrm{HNO}_{3}$, and $1 \mathrm{ml}$ of $3 \mathrm{M} \mathrm{HNO}_{3}$. The $\mathrm{Sr}$ fraction was obtained by passing $5 \mathrm{ml}$ of $0.05 \mathrm{M} \mathrm{HNO}_{3}$ through a filter. During sample decomposition and chemical separation, the recovery yield was $>95 \%$. The total procedural blank for $\mathrm{Sr}$ was $<1 \mathrm{ng}$, which was negligible compared to the sample size used in this study. For the isotopic measurement, the final solutions were diluted to a $\mathrm{Sr}$ concentration of $300 \mu \mathrm{g} \mathrm{g}^{-1}$ using $2 \% \mathrm{HNO}_{3}$.

At Okayama University, $\mathrm{Sr}$ was separated by passing it through cation exchange resin in $2 \mathrm{M} \mathrm{HCl}(1 \mathrm{ml}$ of AG50 $\times$ $12,200-400$ mesh, packed in a size $S$ polypropylene column (Muromachi Chemical Inc.)). To achieve complete separation of $\mathrm{Rb}$, the $\mathrm{Sr}$ separation was repeated twice. The total procedural blank was $\sim 30 \mathrm{pg}$, which was insignificant relative to the amount of $\mathrm{Sr}$ extracted.

\section{Sr Isotope Ratio Determinations: Reproducibility and Accuracy MC-ICP-MS}

The MC-ICP-MS used in this study was a Nu Plasma II $(\mathrm{Nu}$ Instruments, UK) at NIES. Although $\mathrm{Sr}$ was isolated from the matrix components and Rb by column chemistry using Sr spec resin, the signal for ${ }^{85} \mathrm{Rb}$ was simultaneously measured for the isobaric correction. As krypton $(\mathrm{Kr})$ is present as a contaminant in the Ar plasma gas, the contribution of $\mathrm{Kr}$ had to be corrected. The mass numbers of 88 (Sr), 87 ( $\mathrm{Sr}, \mathrm{Rb}), 86$ (Sr, Kr), 85 (Rb), 84 $(\mathrm{Sr}, \mathrm{Kr}), 83(\mathrm{Kr})$, and $82(\mathrm{Kr})$ were detected using individual Faraday cups. The preamplifier gains associated with each Faraday cup were calibrated daily. The operating conditions (e.g., the torch position, Ar gas flow rates, and lens settings) were adjusted to maximize the signal intensity of ${ }^{88} \mathrm{Sr}$ (sensitivity of ${ }^{88} \mathrm{Sr}$ in $300 \mathrm{ng} \mathrm{g}^{-1}$ was typically $\sim 10 \times 10^{-11} \mathrm{~A}$ ). Details of the operation are summarized in Table $1 .{ }^{83} \mathrm{Kr}$ and ${ }^{85} \mathrm{Rb}$ were monitored for the isobaric correction of ${ }^{86} \mathrm{Kr}$ contribution to ${ }^{86} \mathrm{Sr}\left({ }^{86} \mathrm{Kr} /{ }^{83} \mathrm{Kr}=1.503\right),{ }^{84} \mathrm{Kr}$ to ${ }^{84} \mathrm{Sr}\left({ }^{84} \mathrm{Kr} /{ }^{83} \mathrm{Kr}=4.955\right)$, and
${ }^{87} \mathrm{Rb}$ to ${ }^{87} \mathrm{Sr}\left({ }^{87} \mathrm{Rb} /{ }^{85} \mathrm{Rb}=0.3856\right)$. These isobaric interferences were corrected by blank subtraction. The ${ }^{87} \mathrm{Sr} /{ }^{86} \mathrm{Sr}$ ratios were corrected for mass fractionation using the exponential law relative to ${ }^{86} \mathrm{Sr} /{ }^{88} \mathrm{Sr}=0.1194$ (Steiger and Jäger, 1977). Because of the instability of the Ar gas flow, cone and slit degradation, and/or cup aging, Sr isotopic ratios may drift during a daylong analysis. To overcome these problems, a sample-standard bracketing technique was used. The ${ }^{87} \mathrm{Sr} /{ }^{86} \mathrm{Sr}$ values of the samples were adjusted using the NIST SRM 987 value of 0.710248 (McArthur et al., 2001).

\section{TIMS}

The Sr isotopic measurements were performed using two TIMS instruments: the TRITON (Thermo Fisher Scientific, Germany) at Kumamoto University and the Finnigan MAT 262 (Thermo Fisher Scientific) at Okayama University. Approximately 200-500 ng Sr was loaded onto a degassed W single filament along with $\mathrm{Ta}-\mathrm{H}_{3} \mathrm{PO}_{4}$ activator, and the ${ }^{87} \mathrm{Sr} /{ }^{86} \mathrm{Sr}$ ratio was measured at ${ }^{88} \mathrm{Sr}$ intensity $3-4 \times 10^{-11} \mathrm{~A}$. The ${ }^{87} \mathrm{Sr} /{ }^{86} \mathrm{Sr}$ ratios were normalized to ${ }^{86} \mathrm{Sr} /{ }^{88} \mathrm{Sr}=0.1194$ (Steiger and Jä;ger, 1977) using an exponential law. To make an interlaboratory comparison of the data possible, NIST SRM 987 was analyzed at both laboratories, and the final ${ }^{87} \mathrm{Sr} /{ }^{86} \mathrm{Sr}$ ratios of the samples were adjusted using the recommended NIST SRM 987 value of 0.710248 (McArthur et al., 2001).

\section{RESULTS AND DISCUSSION}

\section{Sr Isotope Measurement Reproducibility and Accuracy}

The reproducibility of the $\mathrm{Sr}$ isotopic compositions of the NIST SRM 987 was monitored during the study period to validate the analytical stability of our operating conditions. The ${ }^{87} \mathrm{Sr} /{ }^{86} \mathrm{Sr}$ ratios of $0.710243 \pm 0.000016(2 \mathrm{SD}, n=74), 0.710254 \pm$ 0.000012 (2SD, $n=15$ ), and $0.710234 \pm 0.000022$ (2SD, $n=$ 16) were obtained during the period of analysis at NIES, Kumamoto University, and Okayama University, respectively. To manage the analytical accuracy of our method, two geological standards, JA-2 and JB-1b, were analyzed at least twice on different days to monitor instrument stability at NIES. The values for the ${ }^{87} \mathrm{Sr} /{ }^{86} \mathrm{Sr}$ isotopic ratios of JA-2 and JB-1b were $0.706315 \pm 0.000022(2 \mathrm{SD}, n=7)$ and $0.704093 \pm 0.000023$ (2SD, $n=8$ ), respectively (Table 2 ). These values were identical within an acceptable error to their literature counterparts (JA-2: $0.706331 \pm 0.000013(2 \mathrm{SD}, n=5)$ in Miyazaki and Shuto, 1998; JB-1b: $0.704095 \pm 0.000012$ (2SD, $n=13)$ in Yuhara et al., 2000). The ${ }^{87} \mathrm{Sr} /{ }^{86} \mathrm{Sr}$ isotopic values of JA-2 and JB-1b, same aliquots prepared at NIES, showed $0.706311 \pm 0.000007$ and $0.706325 \pm 0.000007$ for JA-2, and $0.704083 \pm 0.000007$ and $0.704084 \pm 0.000006$ for JB-1b at Kumamoto University (the analytical error is described in 2SE, and 150 ratios were taken in a single measurement) (Table 2). The $\mathrm{Sr}$ isotopic composition of JA-2 was also measured at Okayama University, showing the ${ }^{87} \mathrm{Sr} /$

${ }^{86} \mathrm{Sr}$ ratios of $0.706295 \pm 0.000024(2 \mathrm{SD}, n=9)$ (Table 2). These results indicate that our technique was robust enough to measure ${ }^{87} \mathrm{Sr} /{ }^{86} \mathrm{Sr}$ ratios. 
TABLE 2 | Sr isotopic compositions of JA-2 and JB-1b.

\begin{tabular}{|c|c|c|c|c|}
\hline \multirow[t]{2}{*}{ Sample } & \multirow[t]{2}{*}{ Instrumentation and Reference } & \multirow[t]{2}{*}{$\mathbf{n}$} & \multicolumn{2}{|c|}{${ }^{87} \mathrm{Sr} /{ }^{86} \mathrm{Sr}$} \\
\hline & & & Mean & 2SD \\
\hline \multirow[t]{5}{*}{$J A-2$} & MC-ICP-MS (NIES) & 7 & 0.706315 & 0.000022 \\
\hline & TIMS (Kumamoto Univ.) & 1 & 0.706311 & $0.000007^{\mathrm{a}}$ \\
\hline & TIMS (Kumamoto Univ.) & 1 & 0.706325 & $0.000007^{\mathrm{a}}$ \\
\hline & TIMS (Okayama Univ.) & 9 & 0.706295 & 0.000024 \\
\hline & Miyazaki and Shuto (1998)b & 5 & 0.706331 & 0.000013 \\
\hline \multirow[t]{4}{*}{$J B-1 b$} & MC-ICP-MS (NIES) & 8 & 0.704093 & 0.000023 \\
\hline & TIMS (Kumamoto Univ.) & 1 & 0.704083 & $0.000007^{\mathrm{a}}$ \\
\hline & TIMS (Kumamoto Univ.) & 1 & 0.704084 & $0.000006^{a}$ \\
\hline & Yuhara et al. $(2000)^{b}$ & 13 & 0.704095 & 0.000012 \\
\hline
\end{tabular}

${ }^{a}$ The analytical error is described in 2SE. 150 ratios (15 cycles $\times 10$ blocks) were taken in a single measurement.

${ }^{b}$ Reported ${ }^{87} \mathrm{Sr} /{ }^{\beta 6} \mathrm{Sr}$ ratios of the NIST SRM 987 are $0.710251 \pm 0.000004\left(2 \sigma_{m}, n=51\right)$ in Miyazaki and Shuto (1998), and 0.710251 in Yuhara et al. (2000). The ${ }^{87} \mathrm{Sr}{ }^{86} \mathrm{Sr}$ ratios of the samples are corrected for interlaboratory bias by adjusting the mean value of the NIST SRM 987 standard run with the samples to the value of 0.710248.

TABLE 3 | Sr isotopic ratios of NIES CRM No. 28 Urban Aerosols.

\begin{tabular}{|c|c|c|c|c|c|c|c|c|}
\hline \multicolumn{2}{|c|}{ Instrumentation } & \multicolumn{2}{|c|}{ Pretreatment } & \multirow{2}{*}{$\begin{array}{c}\text { Bottle } \\
\text { No. }\end{array}$} & \multirow{2}{*}{$\begin{array}{l}\text { Number of } \\
\text { subsampling }\end{array}$} & \multirow{2}{*}{$\begin{array}{c}\text { Number of } \\
\text { measurements } \\
\text { for each } \\
\text { subsample }\end{array}$} & \multicolumn{2}{|c|}{${ }^{87} \mathrm{Sr} /{ }^{86} \mathrm{Sr}$} \\
\hline & & Decomposition & Sr separation & & & & Mean & 2SD \\
\hline \multirow{4}{*}{$\begin{array}{l}\text { MC-ICP-MS } \\
\text { (NIES) }\end{array}$} & \multirow[t]{4}{*}{ Nu Plasma II } & \multirow{4}{*}{$\begin{array}{l}\text { Hotplate with } \mathrm{HNO}_{3} / \\
\mathrm{HClO}_{4} / \mathrm{HF} \text { mixture }\end{array}$} & \multirow[t]{4}{*}{ Sr spec resin } & 044 & 3 & 2 & 0.710221 & 0.000014 \\
\hline & & & & 375 & 3 & 2 & 0.710233 & 0.000024 \\
\hline & & & & 597 & 3 & 2 & 0.710228 & 0.000015 \\
\hline & & & & & & Mean & 0.710227 & 0.000019 \\
\hline \multirow{4}{*}{$\begin{array}{l}\text { TIMS } \\
\text { (Kumamoto } \\
\text { Univ.) }\end{array}$} & \multirow[t]{4}{*}{ TRITON } & \multirow{4}{*}{$\begin{array}{l}\text { Hotplate with } \mathrm{HNO}_{3} / \\
\mathrm{HClO}_{4} / \mathrm{HF} \text { mixture }\end{array}$} & \multirow[t]{4}{*}{ Sr spec resin } & \multirow{4}{*}{$\begin{array}{l}044^{\mathrm{a}} \\
375^{\mathrm{a}} \\
597^{\mathrm{a}}\end{array}$} & & 4 & 0.710229 & 0.000013 \\
\hline & & & & & & 4 & 0.710226 & 0.000012 \\
\hline & & & & & & 4 & 0.710233 & 0.000009 \\
\hline & & & & & & Mean & 0.710229 & 0.000011 \\
\hline $\begin{array}{l}\text { TIMS } \\
\text { (Okayama } \\
\text { Univ.) }\end{array}$ & $\begin{array}{l}\text { Finnigan } \\
\text { MAT } 262\end{array}$ & $\begin{array}{l}\text { High-pressure bomb with } \\
\mathrm{HNO}_{3} / \mathrm{HF} / \mathrm{HClO}_{4}\end{array}$ & $\begin{array}{l}\text { Cation exchange resin, } \\
\text { AG50 × 12, 200-400 mesh }\end{array}$ & 035 & 1 & 12 & 0.710226 & 0.000019 \\
\hline
\end{tabular}

${ }^{a}$ Sample aliquots, decomposed and pretreated at NIES, were analyzed at Kumamoto University. Average internal precisions were $\pm 0.000013, \pm 0.000007$, and \pm 0.000009 (2SE) at NIES, Kumamoto University, and Okayama University, respectively.

\section{Homogeneity of Sr Isotopic Compositions for NIES CRM No. 28}

Table 3 shows the Sr isotopic ratio of NIES CRM No. 28. Withinand between-bottle were evaluated using MC-ICP-MS at NIES, yielding ${ }^{87} \mathrm{Sr} /{ }^{86} \mathrm{Sr}$ isotopic ratios of $0.710227 \pm 0.000019$ (2SD, $n=18$ ). The uncertainty of the Sr isotopic values is an expanded uncertainty determined using a coverage factor $k=2$, which corresponded to a confidence interval of $\sim 95 \%$. To investigate the homogeneity of the isotopic results in CRM (Table 4), the ${ }^{87} \mathrm{Sr} /{ }^{86} \mathrm{Sr}$ isotopic ratios were tested using a one-way analysis of variance (ANOVA). The between-bottle variation was not statistically significant $\left(p>0.05\right.$ and $\left.F_{\text {calculated value }}<F_{\text {critical value }}\right)$ as evaluated by one-way ANOVA. Therefore, when applied to the $\mathrm{Sr}$ isotopic ratios presented in this study, the CRM was homogeneous.

\section{Interlaboratory Studies}

For the MC-ICP-MS vs. TIMS comparison, the Sr isotopic ratios of the three CRM samples (bottle No. 044, 375, and 597), which had been digested and processed for Sr separation at NIES, were measured by TIMS at the Kumamoto University to confirm the consistency of the
TABLE 4 | ANOVA data from the homogeneity study for the Sr isotope.

\begin{tabular}{lccccc}
\hline & F value & p value & $\begin{array}{c}\text { F critical } \\
\text { value }\end{array}$ & $\boldsymbol{s}_{\text {bb }}(\%)$ & $\boldsymbol{u}_{\text {bb }}(\%)$ \\
\hline${ }^{87} \mathrm{Sr} /{ }^{86} \mathrm{Sr}$ & 2.403 & 0.1244 & 3.682 & 0.0006 & 0.0002 \\
\hline
\end{tabular}

${ }^{87} \mathrm{Sr} /{ }^{86} \mathrm{Sr}$ isotopic ratios due to different analytical instruments: NIES was $0.710227 \pm 0.000019(2 \mathrm{SD}, n=18)$ and Kumamoto University was $0.710229 \pm 0.000011(2 \mathrm{SD}, n=12)$ (Figure 1; Table 3).

For sample decomposition and $\mathrm{Sr}$ separation, different methods were performed to evaluate bias during sample digestion and Sr separation at NIES and Okayama University. During the decomposition of the $\mathrm{HNO}_{3} / \mathrm{HClO}_{4} / \mathrm{HF}$ mixture using a hotplate at NIES, undissolved residues were observed, whereas a high-pressure bomb with $\mathrm{HNO}_{3} / \mathrm{HF} / \mathrm{HClO}_{4}$ at Okayama University achieved complete digestion. The ${ }^{87} \mathrm{Sr} /$ ${ }^{86} \mathrm{Sr}$ isotopic ratio obtained at Okayama University was $0.710226 \pm 0.000019(2 \mathrm{SD}, n=12)$ (Figure 1; Table 3). Despite the incomplete dissolution at NIES, the ${ }^{87} \mathrm{Sr} /{ }^{86} \mathrm{Sr}$ 


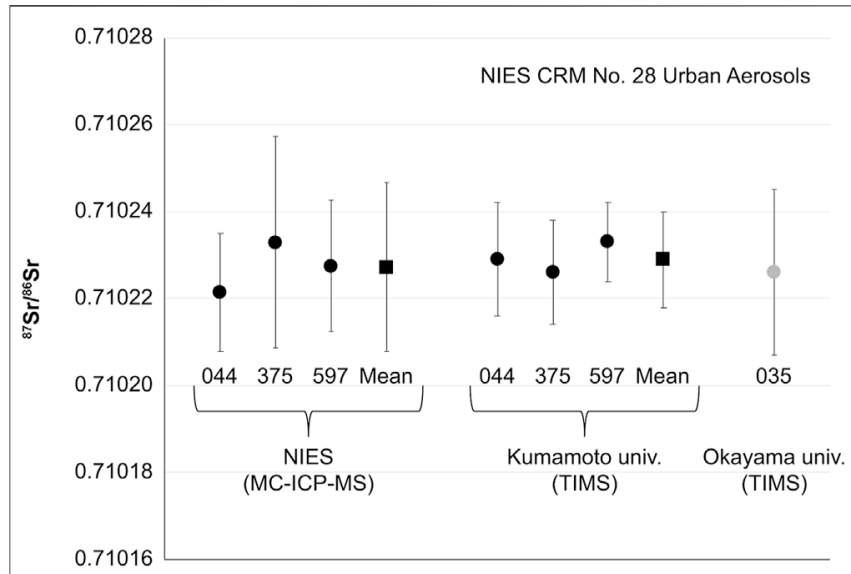

FIGURE $1{ }^{87} \mathrm{Sr} /{ }^{86} \mathrm{Sr}$ ratios of NIES CRM No. 28 Urban Aerosols. All Sr isotopic data were adjusted to the NIST SRM $987{ }^{87} \mathrm{Sr} /{ }^{86} \mathrm{Sr}$ value of 0.710248 .

isotopic ratio was consistent with the latter. Thus, the NIES CRM No. 28 Urban Aerosols was homogeneous enough for the $\mathrm{Sr}$ isotopic measurement of $100-200 \mathrm{mg}$ subsamples using the methods described in Sample Preparation. This CRM will be of great value for the analytical quality assurance of environmental monitoring studies of PM.

\section{Potential CRM Emission Sources}

The present study investigates the use of ${ }^{87} \mathrm{Sr} /{ }^{86} \mathrm{Sr}$ isotope systematics to help determine the origin of atmospheric aerosols. By characterizing the isotopes of ambient PM, potential sources of pollution near sampling sites can be identified, and their contribution to the contents of PM can be estimated. As a test, we compared the ${ }^{87} \mathrm{Sr} /{ }^{86} \mathrm{Sr}$ ratio of NIES CRM No. 28 with those determined by a previous source determination study. Widory et al. (2010) analyzed 63 samples of ambient $\mathrm{PM}_{2.5}$ and 23 samples of ambient total suspended particle (TSP) collected at various locations around Beijing from September 2005 to September 2006. The ${ }^{87} \mathrm{Sr} /{ }^{86} \mathrm{Sr}$ ratios of $\mathrm{PM}_{2.5}$ and TSP ranged from 0.7085 to 0.7108 , with the TSP having a larger variation. They also reported the ${ }^{87} \mathrm{Sr} /{ }^{86} \mathrm{Sr}$ ratios of potential emission sources near Beijing; coal combustion yielded aerosols with the lowest ${ }^{87} \mathrm{Sr} /{ }^{86} \mathrm{Sr}(0.708970-0.709492)$, smelter-derived particles produced the greatest radiogenic value (0.712064), and cement factories created particles with intermediate ${ }^{87} \mathrm{Sr} /{ }^{86} \mathrm{Sr}$ (0.709963-0.710528). They concluded that $\mathrm{Sr}$ in atmospheric PM in Beijing was mainly controlled by coal combustion and to a lesser extent by cement plants and/or smelters. Although sampling periods of the CRM, $\mathrm{PM}_{2.5}$ and TSP overlapped only for 1 year, and the ${ }^{87} \mathrm{Sr} /{ }^{86} \mathrm{Sr}$ ratio of CRM was a 10 -years integral, the $\mathrm{CRM}{ }^{87} \mathrm{Sr} /{ }^{86} \mathrm{Sr}$ ratio plotted within the range of the reported ratios for $\mathrm{PM}_{2.5}$ and TSP and near those of cement factories and coal combustion (Figure 2). The ${ }^{87} \mathrm{Sr} /{ }^{86} \mathrm{Sr}$ ratio of potential end-members, soil (0.711784-0.714797) and smelters, were significantly lower than that of the CRM.

To gain more insight into the sources of the CRM, enrichment factors (EFs) were calculated related to the Earth's upper continental crust (Taylor and McLennan, 1995) with Fe as the reference element (3.50\%). The mass fractions of the CRM metallic elements were reported by Mori et al. (2008). EFs $>10$ of the selected element (regarding anthropogenic sources), were higher in the order of Sb (120.5), As (72.1), Cd (68.5), Pb (24.2), Mo (22.7), and $\mathrm{Zn}$ (19.3) (Table 5). Some previous studies have reported that the major source of $\mathrm{Sb}$ and $\mathrm{Cu}$ in urban atmospheres was brake abrasion particles (Hjortenkrans et al., 2007; Iijima et al., 2007). However, CRM Cu EFs were not as high as $\mathrm{Sb}\left(\mathrm{EF}_{\mathrm{Cu}}=5.0\right)$. High Sb EFs were also found in aerosols collected in Beijing from 2001 to 2006, and coal combustion was suggested as a possible extra source of Sb (Okuda et al., 2008). In addition, coal combustion has been considered a major source of As, the second-highest CRM EF in aerosols (Kowalczyk et al., 1798; Wang et al., 1999).

As a preliminary result, another fingerprint tracer, $\mathrm{Pb}$ isotopic composition, was obtained for the CRM at the Institut des Sciences Analytiques et de Physico-chimie pour l'Environnement et les Matériaux using MC-ICP-MS (Nu Instrument, UK) combined with a desolvator nebulizer unit (DSN-100, Nu Instrument). The $\mathrm{Pb}$ isotopic compositions of the NIES CRM No. 28 and other aerosol samples are summarized in Table 6. Combining the isotope systematics $\left({ }^{206} \mathrm{~Pb} /{ }^{204} \mathrm{~Pb}\right.$ and $\left.{ }^{87} \mathrm{Sr} /{ }^{86} \mathrm{Sr}\right)$ yield constraints for the source of the Beijing aerosols (see Figure 3), the results showed the impact of emissions from coal combustion and cement plants. The volume size distribution of the CRMs showed that particles with a diameter of $\sim 7 \mu \mathrm{m}$ were present with the highest frequency (Mori et al., 2008). According to $\mathrm{Pb}$ concentrations and $\mathrm{Pb}$ isotopic compositions, Widory et al. (2010) suggested that $\mathrm{PM}_{2.5}$ samples are expected to be primarily influenced by activities such as lead refining, while the coarser TSP fraction is attributed to activities such as coal combustion or emissions from cement plants. The average ${ }^{207} \mathrm{~Pb} /{ }^{206} \mathrm{~Pb}$ value and $\mathrm{Pb}$ concentration of aerosols from lead refining plants, coal combustion, and cement factories are $0.8668 \pm 0.031$ and $920,967 \pm 165,969 \mathrm{ppm}(2 \mathrm{SD}, n=6), 0.8583 \pm 0.179$ and $109 \pm$

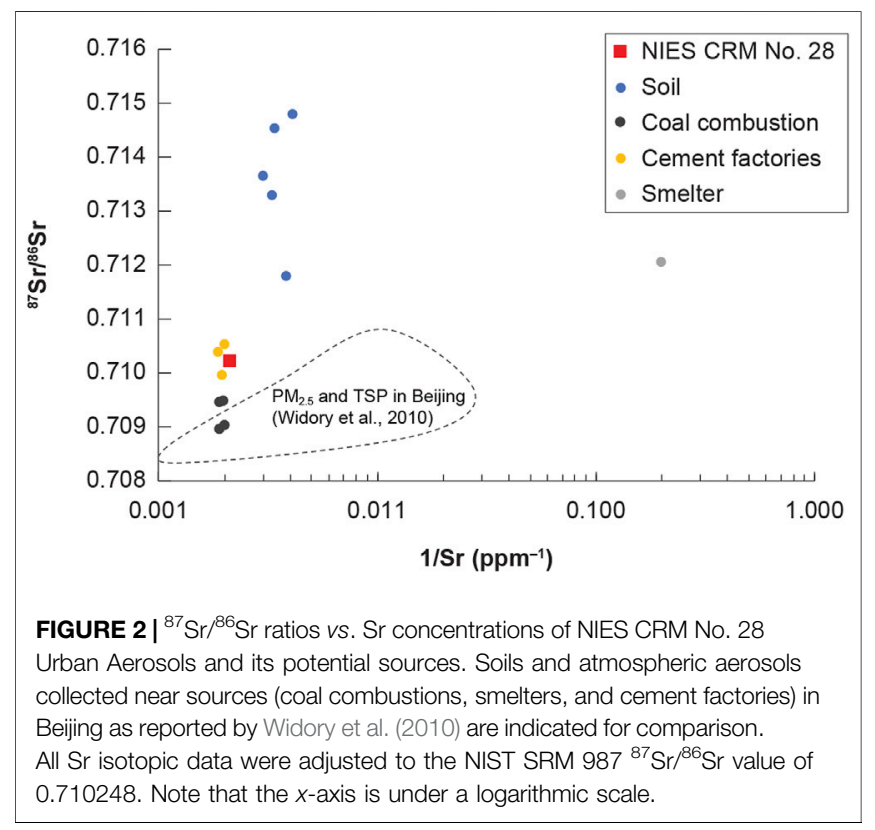


TABLE 5 | Enrichment factors (EFs) of >10 NIES CRM No. 28 and possible anthropogenic sources.

\begin{tabular}{|c|c|c|c|}
\hline Element & EF & $\begin{array}{l}\text { Possible } \\
\text { anthropogenic sources }\end{array}$ & References \\
\hline $\mathrm{Sb}$ & 120.5 & $\begin{array}{l}\text { Abrasion of vehicle brake linings, coal combustion, mining and smelting } \\
\text { activities, electronic devices, road traffic, waste incineration, and the } \\
\text { incineration of sewage sludge }\end{array}$ & $\begin{array}{l}\text { Klumpp et al. (2009); Bech et al. (2012); Nriagu and Pacyna (1988); Okuda } \\
\text { et al. (2008); Tian et al. (2012); Wang et al. (2003) }\end{array}$ \\
\hline As & 72.1 & $\begin{array}{l}\text { Coal combustion, copper metallurgy, power plants, building materials, and } \\
\text { electronics industries }\end{array}$ & $\begin{array}{l}\text { Kowalczyk et al.(1798); Wang et al. (1999); Nriagu and Pacyna (1988); } \\
\text { Christodouilidou et al. (2012); Cucu-Man and Steinnes (2013); Yang et al. } \\
\text { (2015) }\end{array}$ \\
\hline $\mathrm{Cd}$ & 68.5 & Abrasion of tire treads and brake linings & Kummer et al. (2009) \\
\hline $\mathrm{Pb}$ & 24.2 & $\begin{array}{l}\text { Gasoline, automobile emissions, abrasion of tire treads, brake linings, } \\
\text { mining, } \mathrm{Pb} \text { ore smelting, fertilizers, pesticides, and pigments }\end{array}$ & Yu et al. (2007); Kummer et al. (2009); Ribeiro de Souza et al. (2012) \\
\hline Mo & 22.7 & $\begin{array}{l}\text { Smelting, chemical industries, electronics industries, mining, } \\
\text { pharmaceuticals, and pesticides }\end{array}$ & Shan et al. (2013); Brankov et al. (2012) \\
\hline $\mathrm{Zn}$ & 19.3 & $\begin{array}{l}\text { Vehicle components (traffic exhaust, tire and brake wear, and lubricating } \\
\text { motor oil), fossil fuel combustion, electroplating, building materials, and } \\
\text { electronics industries }\end{array}$ & $\begin{array}{l}\text { Fujiwara et al. (2011); Huston et al. (2012); Mendiguchia et al. (2007); } \\
\text { Robert-Sainte et al. (2009) }\end{array}$ \\
\hline
\end{tabular}

EFs were calculated relative to the Earth's upper continental crust (Taylor and McLennan, 1995), and Fe was used as the reference element in this study (3.50\%).

TABLE 6 | Pb isotopic compositions for aerosols.

\begin{tabular}{|c|c|c|c|c|c|c|}
\hline Sample & Reference & ${ }^{206} \mathrm{~Pb} /{ }^{204} \mathrm{~Pb}$ & ${ }^{207} \mathrm{~Pb} /{ }^{204} \mathrm{~Pb}$ & ${ }^{208} \mathrm{~Pb} /{ }^{204} \mathrm{~Pb}$ & ${ }^{206} \mathrm{~Pb} /{ }^{207} \mathrm{~Pb}$ & ${ }^{208} \mathrm{~Pb} /{ }^{207} \mathrm{~Pb}$ \\
\hline \multirow[t]{2}{*}{ NIES CRM No. 28} & This study & 17.859 & 15.567 & 38.000 & 1.14719 & 2.44105 \\
\hline & $(2 \mathrm{SD}, n=3)$ & 0.008 & 0.005 & 0.017 & 0.00023 & 0.00026 \\
\hline Aerosol in Beijing & Bing-Quan et al. (2002) & 17.78 & 15.49 & 37.85 & 1.148 & 2.444 \\
\hline Vehicle exhaust (leaded) in Shanghai & Chen et al. (2005) & & & & 1.11 & 2.434 \\
\hline Vehicle exhaust (unleaded) in Shanghai & Chen et al. (2005) & & & & 1.147 & 2.435 \\
\hline Cement in Beijing & Widory et al. (2010) & 18.064 & & & 1.161 & \\
\hline \multirow[t]{2}{*}{ Beijing Jingeng Thermal Power Co. Ltd (Shijingshan district) } & Widory et al. (2010) & 18.879 & & & 1.155 & \\
\hline & & 18.873 & & & 1.154 & \\
\hline
\end{tabular}

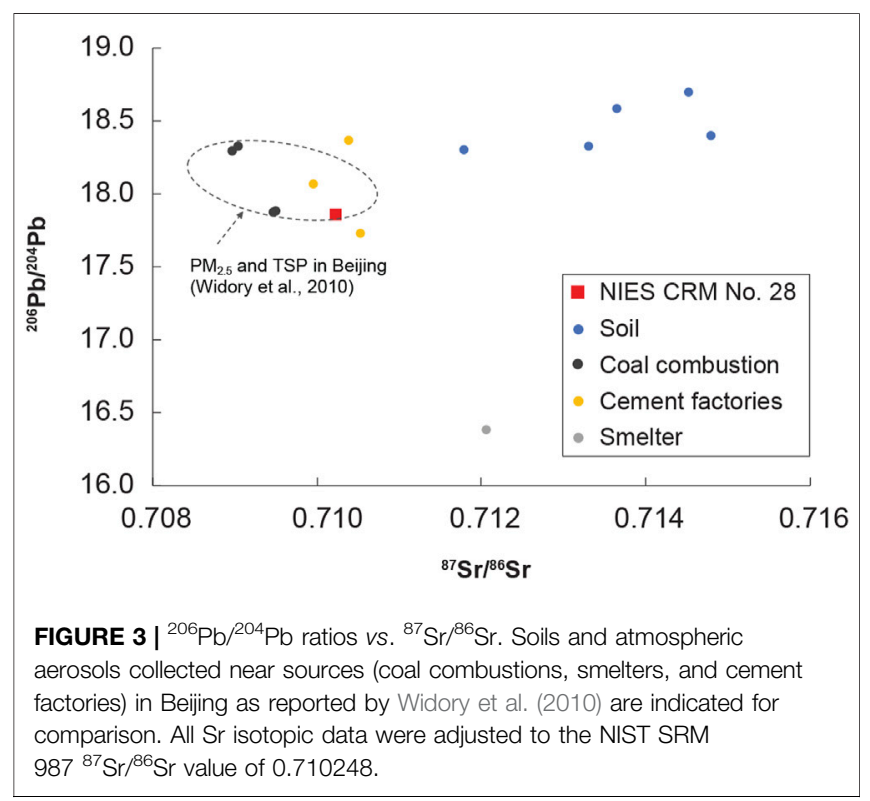

$14 \mathrm{ppm}(2 \mathrm{SD}, n=4)$, and $0.8616 \pm 0.278$ and $21 \pm 16 \mathrm{ppm}(2 \mathrm{SD}$, $n=3$ ), respectively (Widory et al., 2010). The Pb concentration of lead refining plants is significantly high compared to that of CRM. The lead refining plants' derived aerosols cannot be the major source, but a minor contribution to the CRM might be possible. A similarity in the Pb isotopic compositions of the CRM and TSPs in leaded gasoline vehicle exhaust from Shanghai was also reported (Chen et al., 2005). Since the complete ban on the use of alkyllead in 2000, atmospheric $\mathrm{Pb}$ emissions have significantly decreased. However, unleaded gasoline still contains a small amount of $\mathrm{Pb}$, inherited from the crude oil, thus it could be a source of contamination (Wang et al., 2003; Bi et al., 2017). The original material for the CRM was recovered before this prohibition and during the phase-out of leaded gasoline, so the $\mathrm{Pb}$ isotopic ratio may record such environmental conditions.

\section{CONCLUSION}

NIES CRM No. 28 Urban Aerosols was originally prepared to certify mass fractions of major and minor elements. In this study, the $\mathrm{Sr}$ isotopic composition of the CRM was determined to provide an appropriate quality assurance/quality control tool for $\mathrm{Sr}$ isotopic analyses of atmospheric particles. To validate and ensure the accuracy of our method, secondary reference materials, JA-2 and JB- $1 \mathrm{~b}$, were pretreated in the same way as the $\mathrm{CRM}$, and $\mathrm{Sr}$ isotopic compositions were measured using MCICP-MS. According to our results regarding within- and betweenbottle variations of CRM subsamples, the CRM was sufficiently homogenous to be used for $\mathrm{Sr}$ isotopic measurements. As part of 
an interlaboratory CRM study, same sample aliquots were measured using TIMS. The results confirmed the consistency of the isotopic ratio using two instruments (MC-ICP-MS vs. TIMS). We also confirmed the consistency of the Sr isotopic composition using different digestion methods (hotplates vs. digestion bombs) and $\mathrm{Sr}$ separation ( $\mathrm{Sr}$ spec resin $v s$. cation exchange resin). The results of our isotopic analysis contribute to the quality assurance of environmental aerosol monitoring studies.

\section{DATA AVAILABILITY STATEMENT}

The original contributions presented in the study are included in the article, further inquiries can be directed to the corresponding author.

\section{REFERENCES}

Bech, J., Corrales, I., Tume, P., Barceló, J., Duran, P., Roca, N., et al. (2012). Accumulation of Antimony and Other Potentially Toxic Elements in Plants Around a Former Antimony Mine Located in the Ribes Valley (Eastern Pyrenees). J. Geochemical Exploration 113, 100-105. doi:10.1016/ j.gexplo.2011.06.006

Bi, X.-Y., Li, Z.-G., Wang, S.-X., Zhang, L., Xu, R., Liu, J.-L., et al. (2017). Lead Isotopic Compositions of Selected Coals, $\mathrm{Pb} / \mathrm{Zn}$ Ores and Fuels in China and the Application for Source Tracing. Environ. Sci. Technol. 51, 13502-13508. doi:10.1021/acs.est.7b04119

Bing-Quan, Z., Yu-Wei, C., and Xiang-Yang, C. (2002). Application of Pb Isotopic Mapping to Environment Evaluation in China. Chem. Speciation Bioavailability 14, 49-56. doi:10.3184/095422902782775335

Brankov, J., Milijašević, D., and Milanović, A. (2012). The Assessment of the Surface Water Quality Using the Water Pollution index: a Case Study of the Timok River (The Danube River Basin), Serbia. Arch. Environ. Prot. 38, 49-61. doi:10.2478/v10265-012-0004-x

Capo, R. C., Stewart, B. W., and Chadwick, O. A. (1998). Strontium Isotopes as Tracers of Ecosystem Processes: Theory and Methods. Geoderma 82, 197-225. doi:10.1016/s0016-7061(97)00102-x

Chen, J., Tan, M., Li, Y., Zhang, Y., Lu, W., Tong, Y., et al. (2005). A lead Isotope Record of Shanghai Atmospheric lead Emissions in Total Suspended Particles during the Period of Phasing Out of Leaded Gasoline. Atmos. Environ. 39, 1245-1253. doi:10.1016/j.atmosenv.2004.10.041

Christodoulidou, M., Charalambous, C., Aletrari, M., Kanari, P. N., Petronda, A., Ward, N. I., et al. (2012). Arsenic concentrations in groundwaters of Cyprus. J. Hydrol. 468-469, 94-100.

Cucu-Man, S.-M., and Steinnes, E. (2013). Analysis of Selected Biomonitors to Evaluate the Suitability for Their Complementary Use in Monitoring Trace Element Atmospheric Deposition. Environ. Monit. Assess. 185, 7775-7791. doi:10.1007/s10661-013-3135-1

De Laeter, J. R., Böhlke, J. K., De Bièvre, P., Hidaka, H., Peiser, H. S., Rosman, K. J. R., et al. (2003). Atomic Weights of the Elements. Review 2000 (IUPAC Technical Report). Pure Appl. Chem. 75, 683-800. doi:10.1351/ pac200375060683

Duarte, R. M. B. O., Matos, J. T. V., Paula, A. S., Lopes, S. P., Ribeiro, S., Santos, J. F., et al. (2017). Tracing of Aerosol Sources in an Urban Environment Using Chemical, Sr Isotope, and Mineralogical Characterization. Environ. Sci. Pollut. Res. 24, 11006-11016. doi:10.1007/s11356-016-7793-8

Fujiwara, F. G., Gómez, D. R., Dawidowski, L., Perelman, P., and Faggi, A. (2011). Metals Associated with Airborne Particulate Matter in Road Dust and Tree Bark Collected in a Megacity (Buenos Aires, Argentina). Ecol. Indicators 11, 240-247. doi:10.1016/j.ecolind.2010.04.007

\section{AUTHOR CONTRIBUTIONS}

$\mathrm{AY}, \mathrm{KY}, \mathrm{DA}, \mathrm{SB}$, and $\mathrm{OD}$ designed the research. $\mathrm{AY}, \mathrm{KN}, \mathrm{MU}$, $\mathrm{KO}, \mathrm{KY}, \mathrm{TS}, \mathrm{KT}, \mathrm{TK}$, and SB performed the analytical work. AY, $\mathrm{KY}$, and TK wrote the manuscript. All the authors discussed the data and revised and approved the final form of the manuscript.

\section{ACKNOWLEDGMENTS}

We acknowledge Dr. M. Nishikawa and Dr. M. Sano of NIES for their helpful discussions. We especially thank two reviewers, Dr. J. R. Ferreira and Dr. A. Satkoski, for the thoughtful and constructive comments, and Prof. R. P. Mason for the efficient editorial handling of this paper. We would also like to thank Enago (www.enago.jp) for the English-language review.

Grousset, F. E., and Biscaye, P. E. (2005). Tracing Dust Sources and Transport Patterns Using $\mathrm{Sr}, \mathrm{Nd}$ and $\mathrm{Pb}$ Isotopes. Chem. Geology. 222, 149-167. doi:10.1016/j.chemgeo.2005.05.006

Hjortenkrans, D. S. T., Bergbäck, B. G., and Häggerud, A. V. (2007). Metal Emissions from Brake Linings and Tires: Case Studies of Stockholm, Sweden 1995/1998 and 2005. Environ. Sci. Technol. 41, 5224-5230. doi:10.1021/es070198o

Huston, R., Chan, Y. C., Chapman, H., Gardner, T., and Shaw, G. (2012). Source Apportionment of Heavy Metals and Ionic Contaminants in Rainwater Tanks in a Subtropical Urban Area in Australia. Water Res. 46, 1121-1132. doi:10.1016/j.watres.2011.12.008

Iijima, A., Sato, K., Yano, K., Tago, H., Kato, M., Kimura, H., et al. (2007). Particle Size and Composition Distribution Analysis of Automotive Brake Abrasion Dusts for the Evaluation of Antimony Sources of Airborne Particulate Matter. Atmos. Environ. 41, 4908-4919. doi:10.1016/j.atmosenv.2007.02.005

Kanayama, S., Yabuki, S., Yanagisawa, F., and Motoyama, R. (2002). The Chemical and Strontium Isotope Composition of Atmospheric Aerosols over Japan: the Contribution of Long-Range-Transported Asian Dust (Kosa). Atmos. Environ. 36, 5159-5175. doi:10.1016/s1352-2310(02)00587-3

Klumpp, A., Ansel, W., Klumpp, G., Breuer, J., Vergne, P., Sanz, M. J., et al. (2009). Airborne Trace Element Pollution in 11 European Cities Assessed by Exposure of Standardised Ryegrass Cultures. Atmos. Environ. 43, 329-339. doi:10.1016/ j.atmosenv.2008.09.040

Kowalczyk, G. S., Choquette, C. E., and Gordon, G. E. (1798). Chemical Element Balances and Identification of Air Pollution Sources in Washington, D.C. Atmos. Environ 12, 1143-1153.

Kummer, U., Pacyna, J., Pacyna, E., and Friedrich, R. (2009). Assessment of Heavy Metal Releases from the Use Phase of Road Transport in Europe. Atmos. Environ. 43, 640-647. doi:10.1016/j.atmosenv.2008.10.007

Lahd Geagea, M., Stille, P., Gauthier-Lafaye, F., and Millet, M. (2008). Tracing of Industrial Aerosol Sources in an Urban Environment Using $\mathrm{Pb}, \mathrm{Sr}$, and $\mathrm{Nd}$ Isotopes. Environ. Sci. Technol. 42, 692-698. doi:10.1021/es071704c

McArthur, J. M., Howarth, R. J., and Bailey, T. R. (2001). Strontium Isotope Stratigraphy: LOWESS Version 3: Best Fit to the Marine Sr-Isotope Curve for 0$509 \mathrm{Ma}$ and Accompanying Look-up Table for Deriving Numerical Age. J. Geology. 109, 155-170. doi:10.1086/319243

Mendiguchía, C., Moreno, C., and Garcíavargas, M. (2007). Evaluation of Natural and Anthropogenic Influences on the Guadalquivir River (Spain) by Dissolved Heavy Metals and Nutrients. Chemosphere 69, 1509-1517.

Miyazaki, T., and Shuto, K. (1998). Sr and Nd Isotope Ratios of Twelve GSJ Rock Reference Samples. Geochem. J. 32, 345-350. doi:10.2343/geochemj.32.345

Mori, I., Sun, Z., Ukachi, M., Nagano, K., McLeod, C. W., Cox, A. G., et al. (2008). Development and Certification of the New NIES CRM 28: Urban Aerosols for the Determination of Multielements. Anal. Bioanal. Chem. 391, 1997-2003. doi:10.1007/s00216-008-2076-y 
Nriagu, J. O., and Pacyna, J. M. (1988). Quantitative Assessment of Worldwide Contamination of Air, Water and Soils by Trace Metals. Nature 333, 134-139. doi: $10.1038 / 333134 \mathrm{a} 0$

Okuda, T., Katsuno, M., Naoi, D., Nakao, S., Tanaka, S., He, K., et al. (2008). Trends in Hazardous Trace Metal Concentrations in Aerosols Collected in Beijing, China from 2001 to 2006. Chemosphere 72, 917-924. doi:10.1016/j.chemosphere.2008.03.033

Ribeiro de Souza, S. C., Adrián López de Andrade, S., Anjos de Souza, L., and Schiavinato, M. A. (2012). Lead Tolerance and Phytoremediation Potential of Brazilian Leguminous Tree Species at the Seedling Stage. J. Environ. Manage. 110, 299-307. doi:10.1016/j.jenvman.2012.06.015

Robert-Sainte, P., Gromaire, M. C., de Gouvello, B., Saad, M., and Chebbo, G. (2009). Annual Metallic Flows in Roof Runoff from Different Materials: Test-Bed Scale in Paris Conurbation. Environ. Sci. Technol. 43, 5612-5618. doi:10.1021/es9002108

Shan, Y., Tysklind, M., Hao, F., Ouyang, W., Chen, S., and Lin, C. (2013). Identification of Sources of Heavy Metals in Agricultural Soils Using Multivariate Analysis and GIS. J. Soils Sediments 13, 720-729. doi:10.1007/ s11368-012-0637-3

Steiger, R. H., and Jäger, E. (1977). Subcommission on Geochronology: Convention on the Use of Decay Constants in Geo- and Cosmochronology. Earth Planet. Sci. Lett. 36, 359-362. doi:10.1016/0012-821x(77)90060-7

Taylor, S. R., and McLennan, S. M. (1995). The Geochemical Evolution of the continental Crust. Rev. Geophys. 33, 241-265. doi:10.1029/95rg00262

Tian, H., Zhao, D., Cheng, K., Lu, L., He, M., and Hao, J. (2012). Anthropogenic Atmospheric Emissions of Antimony and its Spatial Distribution Characteristics in China. Environ. Sci. Technol. 46, 3973-3980. doi:10.1021/es2041465

Wang, C.-F., Chang, C. Y., Chin, C. J., and Men, L. C. (1999). Determination of Arsenic and Vanadium in Airborne Related Reference Materials by Inductively Coupled Plasma-Mass Spectrometry. Analytica Chim. Acta 392, 299-306. doi:10.1016/s0003-2670(99)00242-1

Wang, W., Liu, X., Zhao, L., Guo, D., and Lu, Y. (2003). Assessment of the PhaseOut of Leaded Gasoline in Tianjin, China Using Isotope Technique. China Environ. Sci. 23, 627-630.

Widory, D., Liu, X., and Dong, S. (2010). Isotopes as Tracers of Sources of lead and Strontium in Aerosols (TSP \& PM2.5) in Beijing. Atmos. Environ. 44, 3679-3687. doi:10.1016/j.atmosenv.2010.06.036

Yamakawa, A., Bérail, S., Amouroux, D., Tessier, E., Barre, J., Sano, T., et al. (2020). $\mathrm{Hg}$ Isotopic Composition and Total Hg Mass Fraction in NIES Certified
Reference Material No. 28 Urban Aerosols. Anal. Bioanal. Chem. 412, 4483-4493. doi:10.1007/s00216-020-02691-9

Yang, Y. Y., Liu, L. Y., Guo, L. L., Lv, Y. L., Zhang, G. M., Lei, J., et al. (2015). Seasonal Concentrations, Contamination Levels, and Health Risk Assessment of Arsenic and Heavy Metals in the Suspended Particulate Matter from an Urban Household Environment in a Metropolitan City, Beijing, China. Environ. Monit. Assess. 187, 409. doi:10.1007/s10661-0154611-6

Yu, K.-F., Kamber, B. S., Lawrence, M. G., Greig, A., and Zhao, J.-X. (2007). High-precision Analysis on Annual Variations of Heavy Metals, lead Isotopes and Rare Earth Elements in Mangrove Tree Rings by Inductively Coupled Plasma Mass Spectrometry. Nucl. Instr. Methods Phys. Res. Section B: Beam Interactions Mater. Atoms 255, 399-408. doi:10.1016/j.nimb.2006.11.127

Yuhara, M., Hamamoto, T., Kondo, H., Ikawa, T., Kagami, H., and Shuto, K. (2000). Rb, Sr, Sm and Nd Concentrations of GSJ, KIGAM and BCR-1 Rock Reference Samples Analyzed by Isotope Dilution Method. Sci. Rep. Niigata Univ. Ser. E (Geology) 15, 23-34.

Conflict of Interest: The authors declare that the research was conducted in the absence of any commercial or financial relationships that could be construed as a potential conflict of interest.

Publisher's Note: All claims expressed in this article are solely those of the authors and do not necessarily represent those of their affiliated organizations, or those of the publisher, the editors and the reviewers. Any product that may be evaluated in this article, or claim that may be made by its manufacturer, is not guaranteed or endorsed by the publisher.

Copyright (c) 2021 Yamakawa, Nagano, Ukachi, Onishi, Yamashita, Shibata, Takamiya, Kani, Bérail, Donard and Amouroux. This is an open-access article distributed under the terms of the Creative Commons Attribution License (CC BY). The use, distribution or reproduction in other forums is permitted, provided the original author(s) and the copyright owner(s) are credited and that the original publication in this journal is cited, in accordance with accepted academic practice. No use, distribution or reproduction is permitted which does not comply with these terms. 